\title{
Non-invasive multiresidue screening methods for the determination of pesticides in heritage collections
}

\author{
lain D Rushworth ${ }^{1}$, Catherine Higgitt ${ }^{2}$, Margaret Smith ${ }^{3}$ and Lorraine T Gibson ${ }^{* *}$
}

\begin{abstract}
Background: This paper describes the development of a novel non-invasive sampling and analysis method that can be used to assess the presence of volatile pesticides on objects held in heritage collections. Vapour phase sampling was conducted using sampling tubes loaded with Tenax-TA ${ }^{\mathrm{TM}}$ and trapped analytes were determined using thermal desorption-gas chromatography-mass spectrometry (TD-GC-MS). The results of this study are presented in a simple 'decision tree' diagram to provide the heritage sector with the best methods to identify the presence of pesticides in collections. To illustrate the use of the methodology developed, the results from two case studies in heritage institutions are presented.

Results: Attempts were made to measure a range of pesticides, known to have been used in heritage collections, in the vapour phase including aldrin, camphor, chloronaphthalene, dichlorodiphenyltrichloroethane (4,4'-DDT), dichlorvos, dieldrin, endrin, a mixture of $\alpha-, \beta-, \gamma$ - and $\delta$-hexachlorocyclohexane (hereafter referred to as $\mathrm{HCH}$ ), naphthalene, and thymol. Of the analytes included in this study, as expected $4,4^{\prime}$-DDT was not sufficiently volatile to be detected in the vapour phase and swab sampling (using hexane) is recommended for this analyte. After method development and validation, the air inside a display case (Swiss Cottage, Isle of Wight) was sampled. The results gave a positive identification for camphor, chloronaphthalene and naphthalene. In contrast, the air around a ceremonial dance mask from the British Museum was analysed but no volatile pesticides were identified. In this case, liquid chromatographic analysis of swab samples from the mask yielded a positive identification of dichlorvos.

Conclusions: The proposed non-invasive sampling methods require sampling of a volume of air around an object. To be detected the pesticide must possess suitable volatility. It was demonstrated that camphor, chloronaphthalene, naphthalene and thymol could be successfully trapped onto Tenax TA ${ }^{\mathrm{TM}}$ sorbent tubes and pseudo-quantitatively analysed using TD-GC-MS. Dichlorvos, HCH, aldrin, dieldrin and endrin were also trapped onto Tenax TA ${ }^{\text {TM }}$ and qualitatively detected by TD-GC-MS. Although a key objective of the developed methods was non-invasive sampling, the low volatility of 4,4'-DDT precluded it from vapour phase monitoring and hexane swabbing followed by HPLC analysis was required.
\end{abstract}

Keywords: Passive sampling, Tenax, Pesticides, Thermal desorption, Gas chromatography, Mass spectrometry

\section{Background}

Methods of pesticide analyses have been largely driven by the food industry [1-3]. In their comprehensive paper of 2000, Filion et al. [4] screened fruit and vegetable samples for 251 known pesticides by extracting pulp with solvent before clean-up on solid phase extraction cartridges. The final extract was pre-concentrated and

\footnotetext{
* Correspondence: lorraine.gibson@strath.ac.uk

${ }^{1}$ WestCHEM, Department of Pure and Applied Chemistry, University of Strathclyde, Glasgow, Scotland, UK

Full list of author information is available at the end of the article
}

analysed by GC-MS or LC-fluorescence. LC-MS/MS has also made an impact on the analyses of pesticides in the food industry, as highlighted in recent papers [5-9]. These methods, although sensitive, accurate and robust are laborious and, more importantly, destroy the material being analysed. Such methods cannot be directly transferred to examine pesticide residues associated with objects in heritage environments. There is therefore a need to develop non-invasive, multiresidue analysis methods suitable for screening objects that have potentially been treated with pesticides in the past.

\section{() Chemistry Central}


Preservation of culturally significant objects has often involved the use of hazardous chemicals such as pesticides, fungicides or other biocides. A number of articles have been published highlighting the range of chemicals used to treat historical objects. Goldberg [10] reviewed records at the Smithsonian Institution (Washington, DC, US) and listed a wide range of chemical species used as pesticidal treatments. Many objects may have been treated many times over their lifetimes and chemicals that have been used at various dates include classes of compounds such as organochlorides, organophosphates, simple aromatic hydrocarbons and commercial biocidal formulations. Using tandem mass spectrometry (MS-MS) Purewal has also shown that $\mathrm{HgCl}_{2}, \mathrm{As}_{2} \mathrm{O}_{3}$, and naphthalene could be detected on the surface of artefacts [11] while Sirois used X-ray fluorescence spectrometry to measure inorganic species [12]. In 2001, Hawks [13] discussed substances suspected of having been used for the pesticidal treatment of artefacts (see Table 1, where chemicals are listed under trivial and trade names). While not an exhaustive list, this table has been included to illustrate the breadth of substances previously used in conservation treatments. A comprehensive list of hazardous chemicals used in the heritage sector has been published by Unger et. al. in 2001 [14]. As yet, the authors have found no consensus as to which sampling approach to take when sampling for these analytes. While publications have recommended sampling using polyurethane foams, $[15,16]$ or solvent extraction of collected dust, [17-19] the need to preconcentrate in both of these methods adds complexity to the analytical procedures.

New methods of pesticide detection, aimed specifically at those working with heritage collections, have been developed and are reported here. Prior to method development a target subset of pesticides was chosen to reflect the typical range of chemicals commonly used in previous treatments. Ten analytes were selected for study and included six organochlorides $(\mathrm{HCH}$, dieldrin, endrin, aldrin, 4,4'-DDT, and chloronaphthalene), one organophosphate (dichlorvos), two aromatic organic compounds (naphthalene and thymol) and one organic terpenoid compound (camphor). Camphor, naphthalene and chloronaphthalene have been used in taxidermy and in natural history collections. Naphthalene and chloronaphthalene were used in mothball formulations or were applied directly. Thymol was used as an antifungal agent, particularly in libraries. 4,4'-DDT has been used extensively to protect heritage collections and $\mathrm{HCH}$ has been used to protect wood from insect attack. Organochloride pesticides dieldrin, aldrin, and endrin have also been applied widely, and dichlorvos was used as an active ingredient in the commercial formulation Vapona.

When analysing objects in heritage collections, it may be necessary to enclose the treated object into a
Table 1 Organic and inorganic chemicals identified by Hawks [13] as having previously been used to treat heritage collections

\begin{tabular}{|c|c|c|}
\hline Substance & $\begin{array}{l}\text { Trade/other } \\
\text { name(s) }\end{array}$ & Chemical family \\
\hline Carbaryl & Sevin & Carbamate \\
\hline Bendiocarb & Ficam & Carbamate \\
\hline Propoxur & Baygon & Carbamate \\
\hline Borax & - & Inorganic \\
\hline Sulfuryl fluoride & Vikane & Inorganic \\
\hline Boric acid & - & Inorganic \\
\hline Alcohol & - & Organic \\
\hline Edolan U & Eulan U33 & Organic \\
\hline Pyrethrins & - & Organic \\
\hline Phenol & Carbolic acid & Organic \\
\hline Hydrogen cyanide & - & Organic \\
\hline Naphthalene & - & Organic \\
\hline Carbon disulfide & - & Organic \\
\hline Lauryl pentachlorophenate & - & Organic \\
\hline Ethylene oxide & - & Organic \\
\hline Formaldehyde & - & Organic \\
\hline Heptachlor & Drinox, heptagram & Organochloride \\
\hline Methoxychlor & $\begin{array}{l}\text { Methoxy-DDT, } \\
\text { methoxide }\end{array}$ & Organochloride \\
\hline Aldrin & - & Organochloride \\
\hline Endrin aldehyde & - & Organochloride \\
\hline Endosulfan II & Phaser, thionex & Organochloride \\
\hline o-Dichlorobenzene & - & Organochloride \\
\hline Cyclohexane hexachlorides & $\mathrm{HCH}$, lindane & Organochloride \\
\hline Carbon tetrachloride & - & Organochloride \\
\hline Dichlorodiphenyltrichloroethane & DDT, Anofex & Organochloride \\
\hline p-Dichlorobenzene & - & Organochloride \\
\hline Chlordane & Belt, Chlor Kil & Organochloride \\
\hline Pentachlorophenol & $\begin{array}{l}\text { Acutox, Dowicide } \\
7\end{array}$ & Organochloride \\
\hline Chloropicrin & PS gas & Organochloride \\
\hline Dieldrin & Alvit, Octalox & Organochloride \\
\hline 1,2,4-Trichlorobenzene & - & Organochloride \\
\hline Ethylene dibromide/dichloride & - & Organohalide \\
\hline Methyl bromide & - & Organohalide \\
\hline Dichlorvos & Vapona & Organophosphate \\
\hline Hydrogen phosphide & Phosphine & Organophosphorus \\
\hline Chlorpyrifos & Dursban & Thiophosphate \\
\hline Diazinon & Knox-out, Dianon & Thiophosphate \\
\hline Malathion & Carbophos & Thiophosphate \\
\hline
\end{tabular}

Substances are grouped by chemical family and include trade names where available. 
suitable container (plastic/glass storage box, or 'tent' around the object) to isolate and concentrate any emissions from the material surface. Tenax $\mathrm{TA}^{\mathrm{Tu}}$ sampling tubes are then used in passive or active sampling mode to collect the emitted vapours. In active sampling mode the air sample is drawn through the sampling tube using a calibrated pump at a rate of approximately $100 \mathrm{~cm}^{3} \mathrm{~min}^{-1}$. When used for personal hygiene monitoring, sampling times are typically $8 \mathrm{~h}$ giving a sampled volume of approximately $50 \mathrm{dm}^{3}$ of air. If the sample is actively collected from a contained space, care should be taken not to extract $>20 \%$ of the enclosed volume to avoid dilution effects (air from the room will be pumped into the sampled space to replace the air pumped out). It is suggested therefore that active sampling is best used when the air space in a storage room or similar is to be monitored whereas passive sampling (which involves collection of a known volume of air by diffusion) is recommended for monitoring small volumes (drawers, cabinets, or contained objects). While passive methods of air sampling take longer (typically days or weeks), they offer further advantages over active air sampling methods: passive sampling has a lower impact on site as there is no requirement to use a pump, sampling can be undertaken in areas where there is no power supply and several sites can be measured simultaneously if multiple sampling tubes are deployed.

\section{Results and discussion}

\section{Validation of chromatographic methods of analyses}

A number of factors will affect the performance of the air sampling method, specifically; (i) the ability of analytes to adsorb onto Tenax $\mathrm{TA}^{\text {тм }}$ (hereafter referred to as Tenax), (ii) the efficiency of extraction by thermal or solvent extraction and (iii) the pesticide's vapour pressure at ambient temperature. To examine the adsorption/thermal desorption performance of Tenax, a standard solution containing all 10 pesticides of interest were spiked $(0-200 \mathrm{ng})$ onto sampling tubes and the desorbed analytes were determined by TD-GC-MS. Calibration data (see Table 2) confirmed that 8 of the pesticides could be determined using

Table 2 Linear regression data from TD-GC-MS method for detected analytes

\begin{tabular}{cc}
\hline Analyte & $\mathbf{R}^{\mathbf{2}}$ value \\
\hline Camphor & 0.9936 \\
Naphthalene & 0.9979 \\
Thymol & 0.9979 \\
Chloronaphthalene & 0.9958 \\
Dichlorvos & 0.9937 \\
Aldrin & 0.8826 \\
HCH & 0.5360 \\
Dieldrin & 0.0642 \\
\hline
\end{tabular}

this method of analysis. The exceptions were endrin and 4,4' -DDT which, when spiked onto Tenax could not be detected in the chromatogram. It was suspected that the high TD temperature at $320^{\circ} \mathrm{C}$ caused thermal decomposition of these two compounds. The regression data for camphor, naphthalene, chloronaphthalene, thymol or dichlorvos all displayed $r^{2}$ values greater than 0.99 indicating that the collection onto, and extraction from, Tenax was efficient. In contrast, the more heavily chlorinated species, (aldrin, $\mathrm{HCH}$ and dieldrin) could be detected, but their regression data were not linear suggesting that the analytes could be detected but not quantitatively using this method.

To allow detection and quantification of the more thermally labile compounds (e.g. detection of endrin and 4,4'DDT) the use of solvents to extract analytes from Tenax sampling tubes was also examined. Tubes spiked with the mixed standard solution were eluted with $10 \mathrm{~cm}^{3}$ of $95: 5 \mathrm{v} /$ $\mathrm{v}$ hexane:isopropyl alcohol (IPA) and the eluate was analysed by liquid chromatography with ultraviolet detection (LC-UV) at $225 \mathrm{~nm}$. The calibration data obtained (see Table 3) confirmed that this method of extraction could be used to quantitatively recover $4,4^{\prime}-\mathrm{DDT}$, and 5 other pesticides, however it was still not possible to quantitatively determine endrin as it co-eluted with dieldrin nor could this method be used to detect camphor or $\mathrm{HCH}$ due to the lack of an active chromophore at $225 \mathrm{~nm}$. Extracted solutions were also pre-concentrated to account for the dilution factors introduced when extracting with $10 \mathrm{~cm}^{3}$ solvent. As the results in Table 4 indicate, the calculated recoveries for spiked Tenax tubes $(n=3)$ were approximately $98 \%$ without pre-concentration and $100 \%$ after pre-concentration. Thus the developed pre-concentration method can be used to detect pesticides when trapped at lower concentration. Finally the solvent extraction solutions were analysed by GC-FID, and without the high thermal desorption temperatures it was possible to detect endrin and 4,4'-DDT, as well as the other 8 pesticides of interest including $\mathrm{HCH}$ and camphor.

\section{Vapour phase monitoring}

After validation of the adsorbent for the target pesticides, the collection method was examined with the aim

Table 3 Linear regression data for Tenax LC-UV method

\begin{tabular}{cl}
\hline Analyte & $\mathbf{R}^{\mathbf{2}}$ \\
\hline Naphthalene & 0.9795 \\
Thymol & 0.9999 \\
Chloronaphthalene & 0.9972 \\
Dichlorvos & 0.9716 \\
Aldrin & 0.9999 \\
Dieldrin/Endrin & 0.9999 \\
4,4'-DDT & 0.9999 \\
\hline
\end{tabular}


Table 4 Recovery values (\%) of standard solutions eluted from Tenax tubes based on peak areas of $5 \mathrm{ng} \mathrm{\mu L}^{-1}$ standard

\begin{tabular}{ccccc}
\hline & $\begin{array}{c}\text { \% Recovered } \\
\mathbf{5}{\mathbf{~ n g ~} \mathbf{L L}^{-1}}^{\text {standard }}\end{array}$ & \%RSD & $\begin{array}{c}\text { \% Recovered } \\
\mathbf{1 0 x} \text { preconcentrated } \\
\mathbf{0 . 5}{\mathbf{~ n g ~} \mathbf{~ L}^{-1} \text { standard }}^{\text {stansD }}\end{array}$ & \% \\
\hline Naphthalene & 97.7 & 4.2 & 96.4 & 5.6 \\
Thymol & 97.7 & 5.9 & 96.5 & 10.5 \\
Chloronaphthalene & 97.5 & 4.8 & 98.0 & 7.9 \\
Dichlorvos & 102.1 & 8.3 & 88.3 & 10.4 \\
Aldrin & 97.6 & 6.8 & 100.7 & 11.1 \\
Dieldrin/Endrin & 97.7 & 6.1 & 102 & 11.7 \\
DDT & 97.2 & 6.4 & 99.7 & 10.9 \\
\hline
\end{tabular}

of providing a non-invasive method of vapour phase monitoring. As expected, vapour phase sampling success was shown to depend primarily on the analytes' vapour pressures, which are listed in Table 5. The data are listed according to vapour density values (which is the maximum concentration of the analyte in the air at a given temperature at equilibrium), calculated by multiplying the vapour pressure and molecular weight and dividing by the gas constant $\left(8.314 \mathrm{~J} \mathrm{~K}^{-1} \mathrm{~mol}^{-1}\right)$ multiplied by the temperature in Kelvin. Examination of vapour pressures alone indicated that potentially the first 7 of the target pesticides listed (camphor - $\mathrm{HCH}$ ) could be trapped onto Tenax from the vapour phase. It was clear that dieldrin, endrin and 4,4'-DDT, which possess vapour pressures approximately $1.3 \times 10^{11}$ times lower than for water, would not be present in appreciable concentrations to be sampled from the vapour phase.

Moreover, it was proposed that passive sampling would be the most appropriate air sampling strategy when used to collect vapour emitting from an object held in a small

Table 5 Vapour pressure data for analytes of interest listed by descending vapour density [20-23]

\begin{tabular}{ccccc}
\hline Pesticide & $\begin{array}{c}\text { Vapour } \\
\text { pressure } \\
\text { mPa }\end{array}$ & Temp ${ }^{\circ} \mathbf{K}$ & MW (g) & $\begin{array}{c}\text { Vapour } \\
\text { density } \\
\left(\mathbf{m g ~ m}^{-3}\right)\end{array}$ \\
\hline $\begin{array}{c}\text { Camphor } \\
\text { Naphthalene }\end{array}$ & 20000 & 293 & 152.2 & $1.2 \times 10^{6}$ \\
Thymol & 6500 & 293 & 128.17 & $3.4 \times 10^{5}$ \\
Chloronaphthalene & 5370 & 293 & 150.22 & $3.3 \times 10^{5}$ \\
Dichlorvos & 4000 & 298 & 162.6 & $2.6 \times 10^{5}$ \\
Aldrin & 290 & 293 & 220.98 & 26246 \\
HCH & 8.6 & 293 & 292.8 & 1031 \\
Dieldrin & 5.6 & 293 & 290.8 & 667 \\
Endrin & 0.4 & 293 & 293.8 & 48 \\
4,4'-DDT & 0.036 & 298 & 294.8 & 4.3 \\
\hline
\end{tabular}

enclosure (drawer, cabinet, box). Tenax sampling tubes are not commonly used in passive mode and so the VOC sampling rates were unknown. To provide an approximate sampling rate $t$-butyl toluene was used as a model substance. Its diffusion coefficient of $0.0571 \mathrm{~cm}^{2} \mathrm{~s}^{-1}$ was used together with Fick's first law of diffusion $[24,25]$ to estimate a VOC sampling rate of approximately $0.78 \mathrm{~m}^{3} \mathrm{~d}^{-1}$. Using this sampling rate, a 2 month sampling period would permit the collection of approximately $50 \mathrm{dm}^{3}$ of air, although sampling times can be reduced if the pesticide vapour is present in air at relatively high concentration. Using this model sampling rate, procedural limits of detection (in conjunction with instrumental LODs defined as $3 \sigma$ of the lowest concentration standard divided by the slope of the calibration curve over 5 replicates) were calculated for 1 and $28 \mathrm{~d}$ sampling periods for the TD-GCMS or LC-UV methods of analyses (see Tables 6 and 7).

\section{Sampling strategies for heritage collections}

In conclusion the results reported here support the proposed adsorbent, Tenax, for sampling a range of pesticides commonly found in heritage institutions. Different vapour phase sampling strategies are proposed (see Figure 1) depending on the analytes of interest, the availability of instrumentation or whether the sampling method is used as a qualitative screening method or if quantitative information is required. For example, if TD-GC-MS is the preferred instrumental technique camphor, chloronaphthalene, naphthalene and thymol can be quantitatively determined whereas dichlorvos, $\mathrm{HCH}$, dieldrin and aldrin can be detected but not quantified. If the trapped analytes are to be removed by solvent extraction then LC-UV can be used to quantitatively determine naphthalene, thymol, chloronapthalene, dichlorvos, aldrin and 4,4'-DDT. To extend the quantitative determination and include camphor, $\mathrm{HCH}$ and endrin, the extraction solution should be analysed by GCFID. For pesticides such as 4,4'-DDT that are insufficiently volatile to be detected in the vapour phase, swab sampling (using hexane) followed by LC-UV or GC-FID analysis offers an alternative sampling and analytical strategy.

Table 6 Instrumental and procedural detection limits for analysis by TD-GC-MS

\begin{tabular}{|c|c|c|c|c|}
\hline Analyte & $\begin{array}{l}\text { Retention } \\
\text { time (min) }\end{array}$ & $\begin{array}{l}\text { Instrumental } \\
\text { LOD (ng) }\end{array}$ & $\begin{array}{c}24 \mathrm{~h} \\
\text { sampling } \\
\left(\mu \mathrm{g} \mathrm{m}^{-3}\right)\end{array}$ & $\begin{array}{c}28 \text { day } \\
\text { sampling } \\
\left(\mu \mathrm{g} \mathrm{m}^{-3}\right)\end{array}$ \\
\hline Camphor & 13.71 & 7.4 & 9.5 & 0.34 \\
\hline Naphthalene & 15.57 & 10.7 & 13.7 & 0.49 \\
\hline Thymol & 17.61 & 8.4 & 10.8 & 0.39 \\
\hline Chloronaphthalene & 18.43 & 12.0 & 15.5 & 0.55 \\
\hline Dichlorvos & 17.24 & 2.9 & 3.7 & 0.13 \\
\hline Aldrin & 25.80 & 52.6 & 35.9 & 1.28 \\
\hline
\end{tabular}


Table 7 Instrumental and procedural detection limits for analysis by LC-UV

\begin{tabular}{|c|c|c|c|c|}
\hline Analyte & $\begin{array}{l}\text { Retention } \\
\text { time (min) }\end{array}$ & $\begin{array}{l}\text { Instrumental } \\
\text { LOD (ng) }\end{array}$ & $\begin{array}{c}24 \mathrm{~h} \\
\text { sampling } \\
\left(\mu \mathrm{g} \mathrm{m}^{-3}\right)\end{array}$ & $\begin{array}{c}28 \text { day } \\
\text { sampling } \\
\left(\mu \mathrm{g} \mathrm{m}^{-3}\right)\end{array}$ \\
\hline Naphthalene & 3.1 & 0.1 & 0.1 & $>0.01$ \\
\hline Thymol & 2.5 & 35.3 & 45.3 & 1.62 \\
\hline Chloronaphthalene & 3.8 & 21.5 & 27.6 & 0.98 \\
\hline Dichlorvos & 2.1 & 21.8 & 27.9 & 1.00 \\
\hline Aldrin & 6.9 & 77.1 & 98.8 & 3.53 \\
\hline Endrin/Dieldrin & 4.4 & 39.2 & 50.3 & 1.79 \\
\hline $4,4^{\prime}-\mathrm{DDT}$ & 5.3 & 36 & 46.2 & 1.65 \\
\hline
\end{tabular}

\section{Case studies}

Case study 1 - vapour phase sampling of a cabinet at Swiss Cottage, Osborne House, Isle of Wight

After the laboratory validation experiments, Tenax sampling tubes were used in the field to assess the quality of air surrounding a range of objects that had previously been treated with pesticides. The first sampling site was an avian taxidermy exhibition at Swiss Cottage, Osborne House, Isle of Wight. The collection is exhibited inside custom-made wood and glass display cases and the stuffed birds were thought to have been previously treated with naphthalene and camphor. Tenax sampling tubes were deployed inside the case for $98 \mathrm{~d}$, giving an approximate sample volume of $70 \mathrm{dm}^{3}$. Using the flow chart (Figure 1) it was shown that the collected air would need to be analysed by GC-FID or TD-GC-MS; here TD-GC-MS was chosen. The resultant chromatograms displayed confirmatory peaks for naphthalene and camphor together with an additional, unexpected pesticide, chloronaphthalene, at vapour phase concentrations of $2.7,2.6$ or $2.8 \mu \mathrm{g} \mathrm{m}{ }^{-3}$, respectively. The measured concentrations were significantly lower than the European Union Workplace Exposure Limit (WEL) of $50 \mathrm{mg} \mathrm{m}^{-3}$ for naphthalene, and $13 \mathrm{mg} \mathrm{m}^{-3}$ for camphor (no WEL exists for chloronaphthalene). While this site was sampled for 98 $\mathrm{d}$, the measured concentrations were 15 times higher than the proposed procedural detection limits and the sampling time could have been reduced to $6 \mathrm{~d}$.

\section{Case study 2 - Torres Strait Islands mask}

The mask from the Torres Strait Islands and now in the collection of the British Museum (item registration number Oc,89+.73, Figure 2) presented an interesting case study due to the number of materials used in its construction; wool, wood, turtle and cowrie shell, fur, feathers, pandanus and hibiscus [26]. While no formal documentation existed regarding the application of pesticide treatments to the object it was suspected that organophosphates had been previously applied. While organophosphate pesticides are typically volatile enough to allow vapour-phase sampling using Tenax (see for example the vapour pressure of dichlorvos in Table 5), initial attempts to undertake vapourphase sampling of the environment around the object yielded no result. It was therefore proposed that in this situation that a conservator would swab selected areas of the object surface. The areas were swabbed with hexane and the hexane swab was eluted into the previous solvent mixture as used to elute Tenax tubes prior to analysis by LCUV. The swabs taken from the mask provided a positive identification for dichlorvos, substantiating the suspected treatment. Although preliminary, the results obtained from the case studies confirmed the potential use of this novel non-invasive method for the determination of selected pesticides in heritage collections.

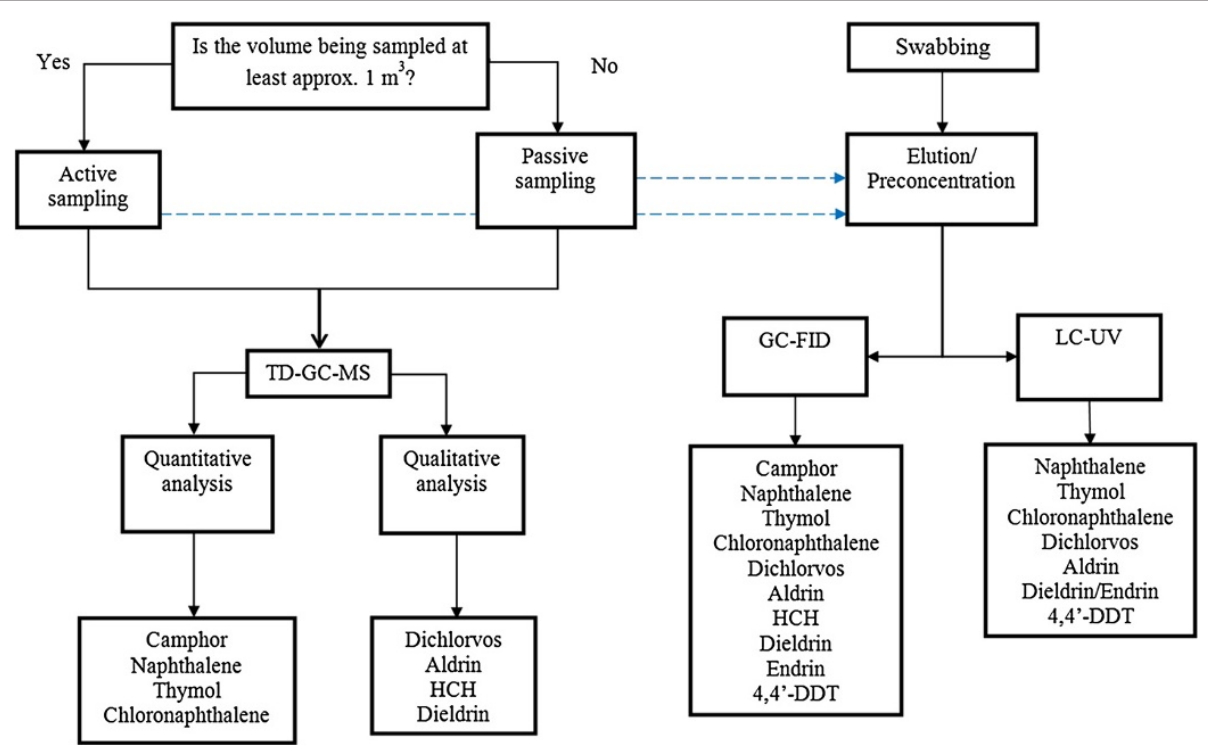

Figure 1 Tenax sampling methods for pesticides in heritage environments. 


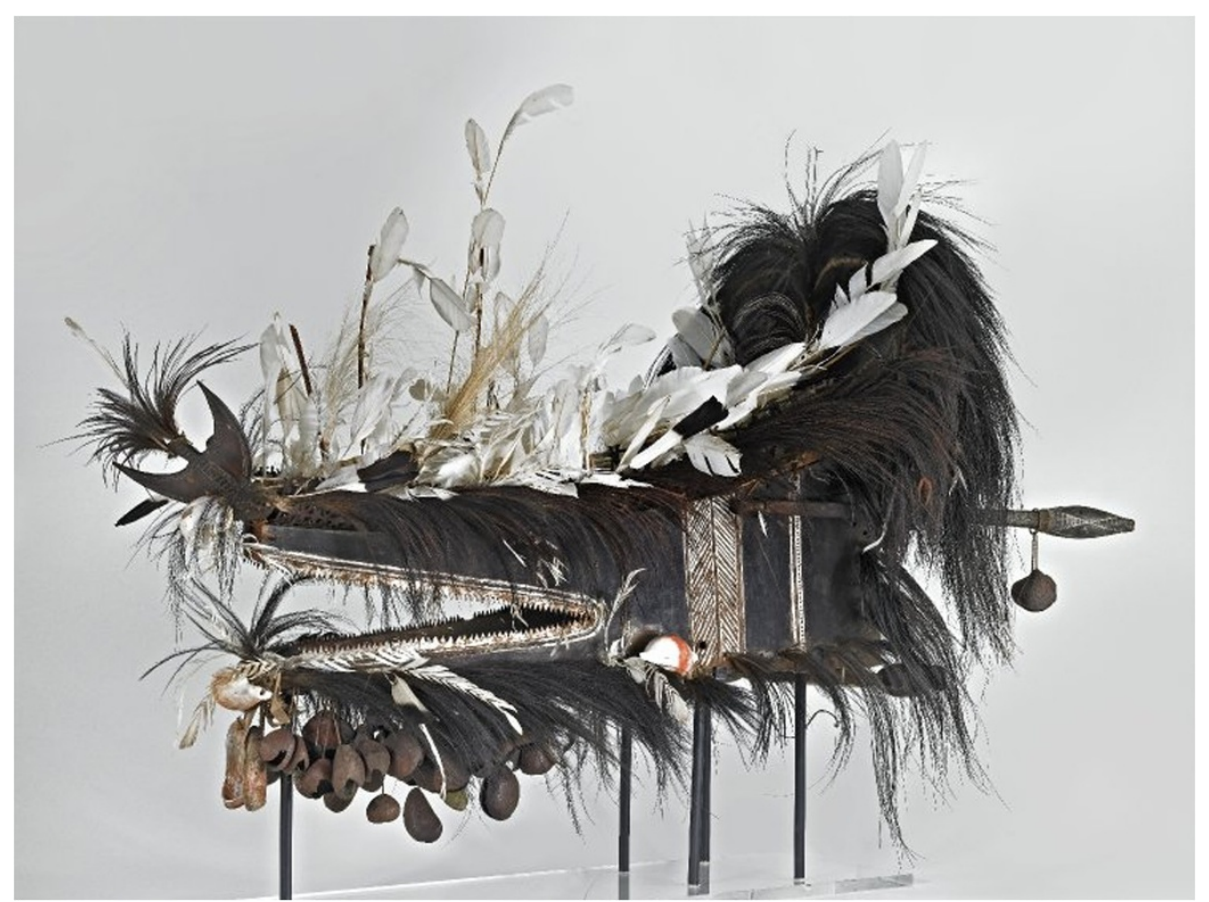

Figure 2 Crocodile head dance mask (Oc,89+.73) Department of Africa, Oceania and the Americas, The British Museum $\odot$ The Trustees of the British Museum.

\section{Conclusions}

This paper presents the use of air sampling as an inferential analysis method to identify the presence of selected pesticides on museum objects. Air sampling around treated objects will permit the determination of camphor, naphthalene, thymol, chloronaphthalene, dichlorvos, aldrin, $\mathrm{HCH}$, dieldrin or endrin, whilst swabbing is required to detect 4,4'-DDT. A 'decision tree' is presented to aid collection custodians and to provide a choice of sampling methods dependent upon suspected treatments. On-site case studies have confirmed that deployment of Tenax air sampling tubes for pesticide detection was minimally invasive, non-contact, and did not require the presence of trained personnel to be present during collection of the vapour phase sample. Despite not commonly being used in passive mode, the results obtained here confirmed that passive sampling using Tenax sampling tubes is suitable. Significantly, the data presented here supports the use of air sampling to determine the presence of pesticides on objects which have been treated in the past and provides the first case study evidence of the developed methods.

\section{Methods}

\section{Preparation of standard solutions}

A standard solution was prepared by measuring approximately $20 \mathrm{mg}$ each of aldrin, camphor, 1-chloronaphthalene, endrin, dichlorvos, dieldrin, 4,4'-DDT, $\mathrm{HCH}$ (1:1:1:1 $\alpha: \beta: \gamma: \sigma$ isomers, Pestanal), naphthalene and thymol into a beaker before quantitative transfer into a $100 \mathrm{~cm}^{3}$ volumetric flask and dilution to volume with 95:5 hexane: IPA. This stock solution was then diluted 10-fold to yield a concentration of approx. $20 \mathrm{ng} \mu \mathrm{L}^{-1}$. All pesticides were of purity $>98 \%$ and purchased from Sigma Aldrich, Gillingham. IPA and hexane were HPLC grade and procured from Fisher Scientific, Loughborough.

\section{Analysis of Tenax sampling tubes by TD-GC-MS}

Analytes trapped onto Tenax sampling tubes were recovered by thermal desorption using a Markes International Unity ${ }^{2}$ thermal desorption unit connected to an Agilent 5890 GC-MS. Each sampling tube was heated for $10 \mathrm{~min}$ at $320^{\circ} \mathrm{C}$ using $\mathrm{He}$ as the carrier gas at $1 \mathrm{~cm}^{3} \mathrm{~min}^{-1}$ and desorbed analytes passed onto a cold trap held at $-30^{\circ} \mathrm{C}$. In the second stage of the desorption process the cold trap was rapidly heated at approximately $99^{\circ} \mathrm{C} \mathrm{sec}^{-1}$ to $300^{\circ} \mathrm{C}$ permitting a sharp band of vapour to pass into the GC-MS.

Helium, at a flow rate of $1 \mathrm{~cm}^{3} \mathrm{~min}^{-1}$, was used as the GC-MS carrier gas with a DB-5MS $(30 \mathrm{~m} \times 250 \mu \mathrm{m} \times$ $0.25 \mu \mathrm{m}$ film thickness) capillary column (Agilent Technologies UK Ltd, Stockport). The GC column was heated using the following conditions: $65^{\circ} \mathrm{C}$ for $5 \mathrm{~min}$, $5^{\circ} \mathrm{C} \mathrm{min}{ }^{-1}$ to $90^{\circ} \mathrm{C}$ held for $5 \mathrm{~min}, 30^{\circ} \mathrm{C} \mathrm{min}{ }^{-1}$ to $180^{\circ} \mathrm{C}$ and held for $5 \mathrm{~min}$ before increasing at $20^{\circ} \mathrm{C} \mathrm{min}^{-1}$ to $220^{\circ} \mathrm{C}$ 
and holding for $5 \mathrm{~min}$ to give a final analysis time of $30 \mathrm{~min}$. Mass spectrometric detection was used in scan mode over 30-450 amu, with an electron energy of $70 \mathrm{eV}$ and a solvent delay of $2 \mathrm{~min}$.

Calibration of the TD-GC-MS was performed by loading conditioned Tenax tubes with $2.5,5,7.5$ or $10 \mu \mathrm{L}$ of the $20 \mathrm{ng} \mu \mathrm{L}^{-1}$ dilutions of the mixed standard solution prepared as described, with one tube being loaded with a solvent blank. The mass of each analyte on the tube was therefore 50,100, 150 and 200 ng respectively, with a 0 ng blank. Loading was performed by injecting the necessary volume directly onto the Tenax in the tube.

\section{Calculation of vapour phase concentrations using naphthalene at Swiss Cottage as an exemplar}

To estimate the pesticide vapour phase concentrations the open ends of the Tenax tubes were considered as 2 passive sampling tubes working in tandem: each end collecting the pesticide molecules by diffusion. The sampling rates were determined by application of Fick's first law of diffusion as given below.

$$
\text { Sampling } \text { Rate }_{\text {Tenax }}=\frac{D A}{L}
$$

where $\mathrm{D}$ is the diffusion coefficient of the pollutant gas passing through the static air layer in the tube (here the model pollutant $t$-butyl toluene was used with a diffusion coefficient of $\left.0.05271 \mathrm{~cm}^{2} \mathrm{~s}^{-1}\right)$, A is the crosssectional area of the tube $\left(0.238 \mathrm{~cm}^{2}\right)$ and $\mathrm{L}$ is the length $(1.5$ or $3.0 \mathrm{~cm})$ from the open end of the tube to the Tenax adsorbent. One end of the tube had a sampling rate of $783 \mathrm{~cm}^{3} \mathrm{~d}^{-1}$ whereas the other end of the tube (with the longer diffusional length) was $391 \mathrm{~cm}^{3} \mathrm{~d}^{-1}$. The sampling tube was exposed for $96 \mathrm{~d}$ giving a total sample volume of approximately $113 \mathrm{dm}^{3}$. After analysis the trapped mass of naphthalene was calculated to be $213 \mathrm{ng}$ which gives an vapour phase concentration $(\mathrm{m} / \mathrm{V})$ of $1.9 \mathrm{ng} \mathrm{dm}^{-3}$ which is equivalent to $1.9 \mu \mathrm{g} \mathrm{m}^{-3}$.

\section{Removal of trapped analytes from Tenax sampling tubes using solvent extraction and analysis by HPLC-UV}

Tenax sampling tubes were back-flushed with $8 \mathrm{~cm}^{3}$ of a hexane:IPA solution at a vol:vol ratio of 95:5 into a $10 \mathrm{~cm}^{3}$ volumetric flask before being diluted to volume with the same solvent. The extracted solution was transferred to a graduated centrifuge tube and reduced in volume, under a stream of $\mathrm{N}_{2}$ at $30^{\circ} \mathrm{C}$, using a Techne FSD400D sample concentrator. The final solution volume was approximately $0.8 \mathrm{~cm}^{3}$, which was diluted to $1 \mathrm{~cm}^{3}$ using the hexane:IPA solution.

The final extracts were analysed by LC-UV. A standard solution containing all 10 analytes of interest was prepared using approximately $20 \mathrm{mg}$ masses dissolved in $100 \mathrm{~cm}^{3}$ 95:5 hexane:IPA, to give a $200 \mathrm{ng} \mu \mathrm{L}^{-1}$ concentration. Instrument calibration was performed by injecting $25,50,100$ or $250 \mu \mathrm{L}$ of the standard solution onto individual Tenax tubes giving loaded analyte masses of 5000, 10000, 20000 and $50000 \mathrm{ng}$, respectively. Elution of calibration tubes using $10 \mathrm{~cm}^{3}$ of 95:5 hexane:IPA gave calibration solutions of $0.5,1$, 2 , or $5 \mathrm{ng} \mu \mathrm{L}^{-1}$. A Tenax sampling tube which had not been loaded with the standard solution was eluted with $10 \mathrm{~cm}^{3}$ of $95: 5$ hexane:IPA to provide a procedural blank.

Extracted solutions were analysed using a Thermo Separation Products LC equipped with TSP UV1000 detector set to $225 \mathrm{~nm}$. Separation was performed on a Jones C18 $4 \mu \mathrm{m}, 4.6 \times 250 \mathrm{~mm}$ column with an isocratic 90:10 acetonitrile:water mobile phase at $1.5 \mathrm{~cm}^{3} \mathrm{~min}^{-1}$ and a $100 \mu \mathrm{L}$ sample loop. Analyte recoveries were calculated by loading $200 \mu \mathrm{L}$ or $25 \mu \mathrm{L}$ of a $250 \mathrm{ng} \mu \mathrm{L}^{-1}$ mixed analyte standard solution onto a Tenax sampling tube. Analytes were removed by solvent extraction using $10 \mathrm{~cm}^{3}$ of 95:5 hexane:IPA. The solution with the lower $25 \mu \mathrm{L}$ loading was preconcentrated 10-fold to give both solutions a final concentration of $5 \mathrm{ng} \mathrm{LL}^{-1}$. Both solutions were injected into the LC-UV system and compared to a reference sample of mixed standard solution at $5 \mathrm{ng} \mu \mathrm{L}^{-1}$ that had not previously been recovered from Tenax. Experiments were repeated in triplicate and recovery values were calculated by comparison and expressed as a mean percentage of the $5 \mathrm{ng} \mu \mathrm{L}^{-1}$ peak area mean.

\section{Analysis of eluted analyte solutions by GC-FID}

The solvent elution protocol is outlined previously. The sample was introduced to the GC-FID via direct injection instead of thermal desorption. The injection port temperature was $220^{\circ} \mathrm{C}$ and the detector temperature was $280^{\circ} \mathrm{C}$. The injection volume was $5 \mu \mathrm{L}$ and used a 1:10 split. $200 \mathrm{ng} \mu \mathrm{L}^{-1}$ standard solutions as prepared above were diluted to give calibration standards over a range of $0-50 \mathrm{ng} \mu \mathrm{L}^{-1}$. As with the TD-GC-MS method, He at a flow rate of $1 \mathrm{~cm}^{3} \mathrm{~min}^{-1}$ was used as the carrier gas with a DB-5MS $(30 \mathrm{~m} \times 250 \mu \mathrm{m} \times 0.25 \mu \mathrm{m}$ film thickness) capillary column. The GC was programmed to give the following conditions for analysis: $65^{\circ} \mathrm{C}$ for $5 \mathrm{~min}, 5^{\circ} \mathrm{C} \mathrm{min}{ }^{-1}$ to $90^{\circ} \mathrm{C}$ held for $5 \mathrm{~min}, 30^{\circ} \mathrm{C} \mathrm{min}{ }^{-1}$ to $180^{\circ} \mathrm{C}$ and held for $5 \mathrm{~min}$ before increasing at $20^{\circ} \mathrm{C} \mathrm{min}{ }^{-1}$ to $220^{\circ} \mathrm{C}$ and holding for $5 \mathrm{~min}$. Final analysis time was $30 \mathrm{~min}$.

\section{Use of Tenax sampling tubes to collect pesticide vapours at case study sites}

Tenax sampling tubes (Markes International Ltd, Llantrisant) were conditioned using a Markes Unity ${ }^{2}$ thermal desorption unit for $30 \mathrm{~min}$ at $320^{\circ} \mathrm{C}$ using $\mathrm{He}$ as the carrier gas. Immediately after conditioning the 
sampling tubes were sealed using brass caps and PTFE ferrules. Sampling tubes were sent to each location by Royal Mail, where they were received and deployed at the sampling site within a few days (stored tubes were kept at room temperature). To deploy the sampling tubes the two brass caps were removed and the sampling tube was placed at the sampling location and exposed in passive mode before being re-sealed and transported back to the laboratory for analysis.

\section{Swabbing}

Swabbing was performed using hexane-soaked cotton wool buds on wooden splints. 10 horizontal strokes and 10 vertical strokes were taken from a sampling area. After swabbing the cotton wool bud was stored in a sealed vial at room temperature before being extracted into $1 \mathrm{~cm}^{3}$ 95:5 hexane:IPA. The extraction solution was analysed by LC-UV as described above.

\section{Competing interests}

The authors declare that they have no competing interests.

\section{Authors' contributions}

IDR performed analyses, designed experiments, interpreted results and wrote the paper. LTG, MS and CH assisted with data interpretation and experimental design, as well as reviewing the article. All authors read and approve the final manuscript.

\section{Acknowledgements}

Funding was gratefully received from the Science and Heritage Program of the AHRC and EPSRC (AH/H032630/1). The authors wish to extend their thanks to Dr David Thickett and staff at English Heritage for their participation in the Osborne House case study, and to staff at the British Museum for allowing sampling of the Torres Strait Islands mask.

\section{Author details}

${ }^{1}$ WestCHEM, Department of Pure and Applied Chemistry, University of Strathclyde, Glasgow, Scotland, UK. ${ }^{2}$ Conservation and Scientific Research, The British Museum, London, UK. ${ }^{3}$ Centre for Textile Conservation and Technical Art History, University of Glasgow, Glasgow, Scotland, UK.

Received: 1 October 2013 Accepted: 28 January 2014

Published: 4 February 2014

\section{References}

1. Chu X, Hu X, Yao H: Determination of 266 pesticide residues in apple juice by matrix solid-phase dispersion and gas chromatography-mass selective detection. J Chromatogr A 2005, 1063:201-210.

2. Cairns T, Chiu KS, Navarro D, Siegmund E: Multiresidue pesticide analysis by ion-trap mass spectrometry. Rapid Commun Mass Spectrom 1993, 7:971-988,

3. Wong JW, Webster MG, Halverson CA, Hengel MJ, Ngim KK, Ebeler SE: Multiresidue pesticide analysis in wines by solid-phase extraction and capillary Gas chromatography-mass spectrometric detection with selective Ion monitoring. J Agric Food Chem 2003, 51:1148-1161.

4. Fillion J, Sauve F, Selwyn J: Multiresidue method for the determination of residues of 251 pesticides in fruits and vegetables by gas chromatography/mass spectrometry and liquid chromatography with fluorescence detection. J AOAC Int 2000, 83:698-713.

5. Giordano A, Fernandez-Franzon M, Ruiz MJ, Font G, Pico Y: Pesticide residue determination in surface waters by stir bar sorptive extraction and liquid chromatography/tandem mass spectrometry. Anal Bioanal Chem 2009, 393:1733-1743.

6. Soler C, James KJ, Picó Y: Capabilities of different liquid chromatography tandem mass spectrometry systems in determining pesticide residues in food: application to estimate their daily intake. J Chromatogr A 2007, 1157:73-84.
7. Pizzutti IR, de Kok A, Zanella R, Adaime MB, Hiemstra M, Wickert C, Prestes OD: Method validation for the analysis of 169 pesticides in soya grain, without clean up, by liquid chromatography-tandem mass spectrometry using positive and negative electrospray ionization. J Chromatogr A 2007, 1142:123-136.

8. Greulich K, Alder L: Fast multiresidue screening of 300 pesticides in water for human consumption by LC-MS/MS. Anal Bioanal Chem 2008, 391:183-197.

9. García-Reyes JF, Molina-Díaz A, Fernández-Alba AR: Identification of pesticide transformation products in food by liquid chromatography/time-of-flight mass spectrometry via "fragmentation - degradation" relationships. Anal Chem 2006, 79:307-321.

10. Goldberg L: A history of pest control measures in the anthropology collections, national museum of natural history, Smithsonian Institution. J Am Inst Cons 1996, 35:23-43.

11. Purewal $\mathrm{V}$ : The identification of four persistent and hazardous residues present on historic plant collections housed within the national museum and galleries of wales. Collection Forum 2001, 16:77-86.

12. Sirois PJ: The analysis of museum objects for the presence of arsenic and mercury: Non-destructive analysis and sample analysis. Collection Forum 2001, 16:65-75.

13. Hawks C: Historical survey of the sources of contamination of ethnographic materials in museum collections. Collection Forum 2001, 16:2-11.

14. Unger A, Schniewind AP, Unger W: Conservation of Wood Artifacts: A Handbook. Berlin: Springer; 2001.

15. Martínez Vidal JL, Egea González FJ, Glass CR, Martínez Galera M, Castro Cano ML: Analysis of lindane, $\alpha$ - and $\beta$-endosulfan and endosulfan sulfate in greenhouse air by gas chromatography. J Chromatogr A 1997, 765:99-108.

16. Salthammer T, Uhde E: Organic Indoor Air Pollutants. Weinheim: WILEY-VCH Verlag GmbH \& Co. KGaA; 2009

17. Weschler CJ, Salthammer T, Fromme H: Partitioning of phthalates among the gas phase, airborne particles and settled dust in indoor environments. Atmos Environ 2008, 42:1449-1460.

18. Schieweck A, Lohrengel B, Siwinski N, Genning C, Salthammer T: Organic and inorganic pollutants in storage rooms of the lower Saxony State Museum hanover, Germany. Atmos. Environ 2005, 39:6098-6108.

19. Schieweck A, Delius W, Siwinski N, Vogtenrath W, Genning C, Salthammer T: Occurrence of organic and inorganic biocides in the museum environment. Atmos Environ 2007, 41:3266-3275.

20. Wickstrom E: Camphor. Oslo: National Poison Center; 1988.

21. WHO: Environmental Health Criteria 130: Endrin. Geneva: World Health Organisation; 1992.

22. WHO: Environmental Health Criteria 91: Aldrin and Dieldrin. Geneva: World Health Organisation; 1989.

23. Worthing CR, Hance RJ: The Pesticide Manual: A World Compendium Farnham: British Crop Protection Council; 1991

24. Gibson LT, Cooksey BG, Littlejohn D, Tennent NH: A diffusion tube sampler for the determination of acetic acid and formic acid vapours in museum cabinets. Anal Chim Acta 1997, 341:11-19.

25. Lugg GA: Diffusion coefficients of some organic and other vapors in Air. Anal Chem 1968, 40:1072-1077

26. British Museum - Collection Database, "Oc,89+.73". www.britishmuseum. org/collection. Online. Accessed 06/02/2014.

doi:10.1186/2050-7445-2-3

Cite this article as: Rushworth et al:: Non-invasive multiresidue screening methods for the determination of pesticides in heritage collections. Heritage Science 2014 2:3. 